\title{
CAPÍTULO 39: AVALIAÇÃO QUALITATIVA DOS CARDÁPIOS DE ALIMENTAÇÃO HOSPITALAR DA SERRA DA IBIAPABA - CE
}

\section{CHAPTER 39: QUALITATIVE EVALUATION OF HOSPITAL FOOD MENU IN SERRA DA IBIAPABA - CE}

\author{
Afonso Marques da Cunha Filho할 Patrícia Mesquita ${ }^{2}$; Valeria Cristina ${ }^{3}$; Beatriz \\ Brandão ${ }^{4}$.
}

\section{Resumo}

O planejamento do cardápio é de extrema importância em qualquer estabelecimento, pois é através dele que podemos garantir que o cliente irá receber uma alimentação devidamente equilibrada e de qualidade. No caso das unidades hospitalares, é ainda mais importante este planejamento das refeições, de forma a garantir uma alimentação equilibrada nutricionalmente, buscando uma alimentação saudável que ajude na manutenção ou recuperação da saúde do paciente. Este estudo tem como objetivo, portanto, avaliar a qualidade dos cardápios executados de algumas unidades hospitalares das cidades da serra da Ibiapaba, estado do Ceará. A pesquisa utilizou para a análise o método de Avaliação Qualitativa das Preparações do Cardápio (AQPC), elaborado por Proença e Vieros (2003). Foi percebido que as refeições oferecidas pelas unidades avaliadas tiveram uma baixa oferta de verduras, legumes e frutas e que algumas UAN's ainda ofertaram alimentos fontes de enxofre e apresentavam repetições de técnicas culinárias em relação as refeições ofertadas, necessitando, assim, de um maior planejamento nesses quesitos.

Palavras-Chave: Analise Qualitativa, Planejamento de Cardápio, Gastronomia.

\begin{abstract}
The planning of meals is of great importance in any establishment, for through it we can ensure towards the client will receive a quality feeding and balanced properly. In case of the hospital units, it is even more important the planning of meals, in order to ensure a nutritionally and balanced diet seeking a healthy feeding that helps with the patient's health maintenance, or your recovery. This study aims to evaluate the quality of the menus from some hospital units of Serra da Ibiapaba, State of Ceará. The research used for analysis the Qualitative Evaluation of the Menu Components - QEMC (in Portuguese: "Availação Qualitativa das Preparações do Cardápio" (AQPC), elaborated by "Proença e Vieros" (2003). Was observed that the meals offered by units have a few supplay of vegetables and fruits, and in some UAN's still offered food sources of sulfur, and presented repetitions of techniques cooking in relation to meals offered, requiring a better planning in these questions.
\end{abstract}

Keywords: Qualitative Analysis, Menu Planning, Gastronomy.

\footnotetext{
${ }^{1}$ Agroindústria, Instituto Federal de Educação, Ciência e Tecnologia do Ceará, afonso.filho70@ hotmail.com

${ }^{2}$ Mestre (a), Instituto Federal de Educação, Ciência e Tecnologia do Ceará, patricia.campos@ifce.edu.br

${ }^{3}$ Mestre (a), Instituto Federal de Educação, Ciência e Tecnologia do Ceará, valeria.nogueira@ifce.edu.br

${ }^{4}$ Doutor (a), Instituto Federal de Educação, Ciência e Tecnologia do Ceará, beatriz.brandao@ifce.edu.br
} 


\section{Introdução}

A serra da Ibiapaba está localizada na região Nordeste, no estado do Ceará, composta por oito cidades, quais sejam: Carnaubal, Croatá, Guaraciaba do Norte, Ibiapina, São Benedito, Tianguá, Ubajara e Viçosa do Ceará. O trabalho foi realizado em seis hospitais localizados em seis cidades da região que aceitaram participar da pesquisa, totalizando 184 cardápios analisados.

As Unidades de Alimentação e Nutrição - UAN tem como papel principal proporcionar para os seus comensais uma alimentação equilibrada nutricionalmente, que apresente uma sanidade adequada, previstas por lei, necessária para manter ou recuperar a saúde dos seus consumidores (VEIROS; PROENÇA, 2003).

Dentro das UAN, cabe a um nutricionista a função de planejar a composição do cardápio. Caso o cardápio seja elaborado por outro profissional, antes de ser executado, deve obrigatoriamente passar por aprovação de um nutricionista, pois este profissional é quem vai garantir que o cardápio esteja balanceado para que os comensais tenham uma refeição devidamente equilibrada (SILVA; MARTINEZ, 2008).

O planejamento do cardápio é muito importante, pois é durante a sua elaboração que se decide a finalidade a que se propõe, assim como qual grupo vai atender: se será para indivíduos saudáveis, que tem como objetivo uma alimentação para manter ou melhorar sua saúde e bemestar ou, ainda, para indivíduos enfermos, grupo com necessidades especiais.

Dentro do universo da saúde, o cardápio e seu dimensionamento pode depender da patologia e das necessidades de uma dieta específica, restrições a determinados alimentos (diabéticos, hipertensos, celíacos etc.). Dentro dessa dimensão, tem-se que considerar o grupo dos intolerantes ou os alérgicos. E também temos o grupo dos vegetarianos que não consome nenhum tipo de carne e o dos veganos que tem uma dieta bem restrita, pois não consome alimentos fontes de proteínas animal (VIEIRA et al., 2015).

O ideal é que o cardápio hospitalar deve respeitar os hábitos alimentares dos pacientes e suas características sociais, religiosas e culturais, sempre levando em conta o hábito alimentar anterior a internação, com o intuito de evitar rejeição e assim evitar problemas de desnutrição e desperdício de alimentos. O cardápio deve ser bem dinâmico e diferenciado buscando a máxima aceitação dos pacientes (ROBERTO, 2013).

Estudo publicado em 2007 avaliou um grupo específico de pacientes cuja doença impacta negativamente o estado nutricional. Os autores observaram recusa alimentar das grandes refeições (almoço e jantar) com preferências por lanches e concluíram o trabalho destacando a importância da aplicação das técnicas de gastronomia e do 
desenvolvimento de cardápio especializado com o objetivo de melhorar a ingestão alimentar e, por consequência, o estado nutricional dos pacientes em questão (LINS, 2013, p. 12).

O maior investimento na gestão hospitalar deve ser na qualificação dos funcionários da cozinha, pois boa estrutura não será suficiente se o colaborador não segue todos os princípios da gastronomia, aliados às exigências higiênico-sanitárias. O treinamento deve ser desde a preparação de cortes dos alimentos até a finalização, pois o aspecto visual é muito importante (LINS, 2013).

Segundo Mirshawka (1994), a palavra hospital deriva do latim hospitalis, adjetivo derivado de hospes (hóspede, estrangeiro, viajante), que também pode ser entendido como "aquele que dá agasalho ou hospeda". faz uma comparação entre o hospital e hotel, pois ambos possuem um início comum, já que a noção de hospitalidade oferecida por esses locais deu origem à palavra acolhimento. Podemos dizer que hospital e hotel são similares, pois ambos têm o objetivo de hospedar, sendo o hospital destinado a tratar enfermidades e a recuperar a saúde do seu cliente. Já o hotel, por sua vez, oferece um ambiente para descanso mental, físico e até de distração.

No que diz respeito à alimentação, ambos dão ênfases bem diferentes. No hotel, o serviço de alimentação busca compor pratos bem elaborados, bastante valorizados devido a suas montagens, tendo uma equipe de cozinha com grande conhecimento técnico e normalmente com um chef renomado. A principal preocupação da Unidade Produtora de Refeição - UPR do hotel é fornecer uma refeição saborosa que agrade o paladar de seus clientes e claro fornecer uma alimentação segura para manter a saúde de seu comensal.

O Serviço de Nutrição e Dietética - SND inserido no hospital tem como principal objetivo a nutrição do enfermo, atendendo aos aspectos nutricionais e sensoriais (BRITO; BEZERRA, 2013) Dessa forma, a alimentação pode ajudar na promoção e recuperação da saúde com grande importância na melhoria do quadro clinico dos pacientes (BORGES et al., 2006).

Todos sabemos que o ambiente hospitalar ainda continua sendo visto como um lugar com péssima comida e, juntamente com o mal-estar causado pelas enfermidades, esse fato pode diminuir a aceitação das dietas pelos pacientes (SOUSA; GLÓRIA; CARDOSO, 2011). É importante que o nutricionista e a equipe do SND planejem CARDOSO as dietas pensando não somente no fator nutricional, mas também no sensorial para que estimule o paciente a ter uma boa aceitação do cardápio planejado (BRITO; BEZERRA, 2013).

Nos hospitais, diferentemente do hotel, a alimentação é menos elaborada, normalmente sem vida e sem sabor, fazendo com que seja um dos fatores com que o paciente não se alimente 
de forma correta ou pelo menos de forma não prazerosa, pois a comida não se torna atrativa. Nos hospitais, a preocupação é garantir uma alimentação microbiologicamente segura e nutricionalmente adequada (PEDROSA, 2007), coerente com o fato de que o ambiente hospitalar normalmente não é um lugar tão aconchegante. Entre um dos poucos serviços que possuem a possibilidade de tornar o tempo de internação mais acolhedor para o enfermo e seus familiares é através da alimentação, que precisa ser capaz não somente de suprir as necessidades básicas para a manutenção e recuperação do paciente (GUIMARÃES, 2007).

O SND é de grande importância, pois se torna responsável pelo acolhimento dos pacientes e familiares (GUIMARÃES, 2007), precisando estar disponível em qualquer momento que seja solicitado, seja por meio do serviço de quarto ou através de lanchonete/restaurante devendo estar à disposição de quem precisar (BOEGER, 2005). O SND deve oferecer cardápios variados para atender também aos públicos que possuem alguma restrição alimentar, não afetando a qualidade nutricional (PEDROSA, 2007).

A enfermeira Nightingale foi uma das primeiras profissionais de enfermagem a falar em seus estudos sobre indicadores de alimentação hospitalar, considerando errados os horários da alimentação e relatos de fome durante o período de internação de pacientes. Sabemos que a alimentação pode trazer várias sensações. Nesse sentido, a gastronomia hospitalar que tem como objetivo unir a dietética prescrita com alimentações saborosas, saudáveis e auxiliar na recuperação do estado nutricional do paciente. Através de suas intervenções técnicas pode proporcionar sensações agradáveis, conforto ou apenas prazer, que podem ajudar a diminuir o sofrimento do paciente hospitalizado (DICKINSON et al., 2005).

A Serra da Ibiapaba localizada no estado do Ceará a 304km da capital Fortaleza sendo reconhecida regionalmente por possuir uma grande variedade de belezas naturais, como cachoeiras e o parque nacional, localizado na cidade de Ubajara, reconhecida também em função do clima frio e a prática de esportes radicais, possui alguns artefatos históricos, tais como engenhos antigos. Os hospitais da serra são de pequeno porte, atendendo aos serviços mais básicos da população, os pacientes com casos mais graves, são transferidos para a cidade de Sobral ou para a capital Fortaleza.

De acordo com os estudos de Souza (2011) as refeições que foram servidas com o foco nos detalhes, tais como a temperatura, a aparência e a cordialidade no serviço oferecido, tendem a aumentar a ingestão pelos enfermos internados reduzindo o desperdício de alimento e a desnutrição. Assim, é de grande importância associar o tratamento assistencial do paciente em uma dieta individualizada por meio de técnicas culinárias, a fim de transformar o ato de se 
alimentar prazeroso, sendo este o maior desafio da gastronomia hospitalar. Este trabalho irá estudar o cenário da alimentação dos hospitais das cidades da Serra da Ibiapaba, com ênfase na análise qualitativa das preparações servidas.

\section{Material e Métodos}

O estudo foi realizado em hospitais municipais da Serra da Ibiapaba, nas cidades de Carnaubal, Guaraciaba do Norte, Ibiapina, São Benedito, Ubajara e Viçosa do Ceará, onde foi analisado no hospital municipal de cada cidade. Foi realizado durante o período do mês de agosto a setembro, através de visitas nos hospitais, com base em ofícios da instituição, solicitando o cardápio de cada unidade aos seus gestores. Cada cidade foi identificada por letras, para manter o anonimato dos hospitais.

A amostra foi composta pela descrição do cardápio do almoço. O cardápio foi coletado durante os meses de agosto e setembro e analisado utilizando a ferramenta de Avaliação Qualitativa das Preparações do Cardápio (AQPC), que aponta itens como: monotonia de cores, técnicas culinárias, montagem dos pratos, presença de alimentos com alto teor de enxofre, presença de doces e frituras na mesma refeição.

Este método AQPC tem a finalidade de avaliar a qualidade geral das refeições seguindo os critérios abaixo (VEIROS; PROENÇA, 2003):

- $\quad$ Presença de fritura: Quantas vezes é servido a opção de frituras ou se servido em dias próximos;

- $\quad$ Cores das preparações: Verifica se o cardápio oferece duas ou mais preparações com a mesma cor;

- $\quad$ Presença de enxofre: Verificar se os cardápios oferecem três ou mais alimentos ricos em enxofre, exceto o feijão que não foi considerado por fazer parte dos hábitos alimentares da região consumir feijão todos os dias;

- $\quad$ Folhas na salada: Se o cardápio oferta ou não algum tipo de salada folhosa;

- Frutas na sobremesa: Verifica se o cardápio oferta fruta na alimentação como sobremesa em razão da oferta de fibras, vitaminas e minerais, recomendadas diariamente;

- $\quad$ Doces na sobremesa: Se o Cardápio oferece doces na sobremesa;

- Oferta de fritura e doces no mesmo dia: Verifica se o cardápio oferece doce nas sobremesas no mesmo dia que oferece fritura;

- $\quad$ Conserva na salada; 
- Presença de carne gordurosa, esses dois itens apesar de fazerem parte do método AQPC, não foram analisados devido não se encaixarem nos cardápios analisados.

O jogo de cores no prato é de grande importância, pois o fator estético visual são, normalmente, o primeiro atrativo. Foi verificada se existia a monotonia de cores, onde se observaram repetições de cores no prato e/ou também repetições nas técnicas culinárias (frituras, cozidos, grelhados) em dias consecutivos.

Sobre os alimentos ricos em enxofre, não indicados para fins terapêuticos, foram considerados os seguintes alimentos: abacate, acelga, aipo, alho, amendoim, batata-doce, brócolis, castanha, cebola, couve-de-bruxelas, couve-flor, ervilha, gengibre, goiaba, jaca, lentilha, maçã, melancia, melão, milho, mostarda, nabo, nozes, ovo, rabanete, repolho e uva. Foi observado, assim, se os cardápios ofereciam três ou mais alimentos dos que foram citados acima.

Para cada item analisado do método AQPC, foi verificada a quantidade de cardápios adequados e inadequados da região, com apresentação em porcentagem. A adequação seguiu a recomendação de Ginani (2011). Foram consideradas "muito satisfatórias" aquelas que obtiveram adequação acima de 85\%; "satisfatórias" de 60 a 84,9\%; “insatisfatórias" de 50 a 59,9\% e "muito insatisfatórias" de 0 a 49,9\%.

Os dados analisados foram realizados por meio de percentuais e a tabulação foi feita pelo programa Microsoft Excel 2016.

\section{Resultados e Discussão}

A avaliação da qualidade dos cardápios das UAN, feita através do método AQPC, permitiu que se identificassem características importantes sobre a qualidade nutricional das refeições oferecidas nas unidades hospitalares da serra. Dos itens analisados em ambos cardápios (Pacientes e Funcionários), o que mais está em adequação é o das sobremesas (doces), tendo em vista que nenhuma das unidades oferece doce para os pacientes e funcionários. Dentre os cardápios analisados, foi possível perceber que nenhum oferecia mais de uma escolha de opção de carne ou acompanhamentos. Somente em alguns casos isolados a refeição é preparada de forma diferenciada, diferenciando a dieta de pacientes e funcionários (Tabela 1 e 2; Gráficos 1 e 2)

O cardápio das cidades A e E é o mesmo para pacientes, acompanhantes e funcionários.

O primeiro item avaliado foi a presença de frutas na refeição, sendo que apenas três cidades ofertam frutas em ambos os cardápios paciente e funcionários. Os cardápios das cidades A e B ofertam uma porção durante três dias da semana, sendo servido suco de fruta nos outros 
dias. A cidade A só oferece abacaxi e é acompanhando uma salada cozida ou crua. Já a cidade D oferece diariamente uma porção de fruta. As mais críticas, são as cidades C, E e F que não ofertam nenhuma porção nos cardápios.

Tabela 1. Percentual de porções servidas nos cardápios oferecidos para os pacientes das unidades hospitalares, no mês de agosto/setembro, da Serra da Ibiapaba, 2018.

\begin{tabular}{|c|c|c|c|c|c|c|c|c|}
\hline \multirow{2}{*}{ Itens analisados do cardápio } & \multicolumn{6}{|c|}{ Cidades } & \multirow{2}{*}{ Região } & \multirow{2}{*}{$\%$} \\
\hline & $\mathrm{A}$ & $\mathrm{B}$ & $\mathrm{C}$ & $\mathrm{D}$ & $\mathrm{E}$ & $\mathrm{F}$ & & \\
\hline Fruta & 12 & 12 & 0 & $28^{*}$ & 0 & 0 & 52 & 28,3 \\
\hline Folhosos & 0 & 0 & 0 & 0 & 0 & 0 & 0 & 0 \\
\hline Cores iguais & 8 & 0 & 0 & $0 * *$ & 20 & 0 & 28 & 10,9 \\
\hline Ricos em enxofre & 8 & 8 & 0 & 0 & 0 & 20 & 36 & 19,6 \\
\hline Doce & 0 & 0 & 0 & 0 & 0 & 0 & 0 & 0 \\
\hline Fritura & 4 & 0 & 0 & 0 & 0 & 0 & 4 & 0 \\
\hline Fritura + Doce & 0 & 0 & 0 & 0 & 0 & 0 & 0 & 0 \\
\hline Técnicas de Preparo & 20 & 12 & 31 & 31 & 8 & 20 & 122 & 66,3 \\
\hline Total de cardápios & 31 & 31 & 31 & 31 & 30 & 30 & 184 & 100 \\
\hline
\end{tabular}

Tabela 2: Percentual de porções servidas nos cardápios oferecidos para os funcionários das unidades hospitalares, no mês de agosto/setembro, da Serra da Ibiapaba, 2018.

\begin{tabular}{|c|c|c|c|c|c|c|c|c|}
\hline \multirow{2}{*}{ Itens analisados do cardápio } & \multicolumn{6}{|c|}{ Cidades } & \multirow{2}{*}{ Região } & \multirow{2}{*}{$\%$} \\
\hline & A & B & $\mathrm{C}$ & $\mathrm{D}$ & $\mathrm{E}$ & $\mathrm{F}$ & & \\
\hline Fruta & 12 & 20 & 0 & 31 & 0 & 0 & 63 & 34,2 \\
\hline Folhosos & 0 & 24 & 0 & 16 & 0 & 0 & 40 & 21,7 \\
\hline Cores iguais & 8 & 0 & 0 & 1 & 20 & 0 & 29 & 11,4 \\
\hline Ricos em enxofre & 8 & 12 & 4 & 12 & 0 & 20 & 56 & 30,4 \\
\hline Doce & 0 & 0 & 0 & 0 & 0 & 0 & 0 & 0 \\
\hline Fritura & 4 & 4 & 4 & 4 & 0 & 4 & 20 & 10,86 \\
\hline Fritura + Doce & 0 & 0 & 0 & 0 & 0 & 0 & 0 & 0 \\
\hline Técnicas de Preparo & 20 & 0 & 20 & 3 & 8 & 4 & 55 & 29,89 \\
\hline Total de cardápios & 31 & 31 & 31 & 31 & 30 & 30 & 184 & 100 \\
\hline
\end{tabular}

$28 *$ O cardápio oferta frutas diariamente. Porém, está descrito nele que a fruta pode ser substituída por suco, dependendo da disponibilidade.

Fonte: Elaborada pelo autor. (2018)

O item de monotonia de cores apresentou dificuldade ao ser analisado, pois alguns cardápios não detalhavam os ingredientes usados. Diante da análise realizada, verificou-se que a cidade $\mathrm{E}$ apresentou mais monotonia de cores. A monotonia de técnicas culinárias também foi observada em todas as unidades. As cidades C e D apresentaram mais repetições com opções cozidas diariamente, destacando que a cidade $\mathrm{C}$ ofereceu frango com legumes, picadinho de carne com legumes ou carne moída com legumes. Enquanto a cidade D ofereceu apenas carne moída com legumes.

Fazendo uma comparação nos cardápios dos funcionários e pacientes, podemos perceber que o cardápio dos funcionários tem mais alimentos ricos em enxofre. No cardápio dos pacientes das cidades A, B e F apresentaram alimentos flatulentos na composição do prato. Analisando o cardápio dos funcionários, apenas a cidade E não apresentou a presença de 
alimento rico em enxofre. A cidade D ofertava batata doce como purê ou era cozida no feijão e a cidade B oferecia salada de repolho. Nas outras cidades, o alimento causador de flatulências foi a cebola, sendo ofertada em farofa acebolada ou nos bifes acebolados. Vale ressaltar que não foi informado no cardápio o uso de cebola como tempero das preparações. Mas sabe-se que culturalmente é bastante comum usar cebola e alho como temperos básicos para quase todas as preparações.

Gráfico 1. Percentual de porções servidas nos cardápios oferecidos para os pacientes das unidades hospitalares, no mês de agosto/setembro, da Serra da Ibiapaba, 2018.

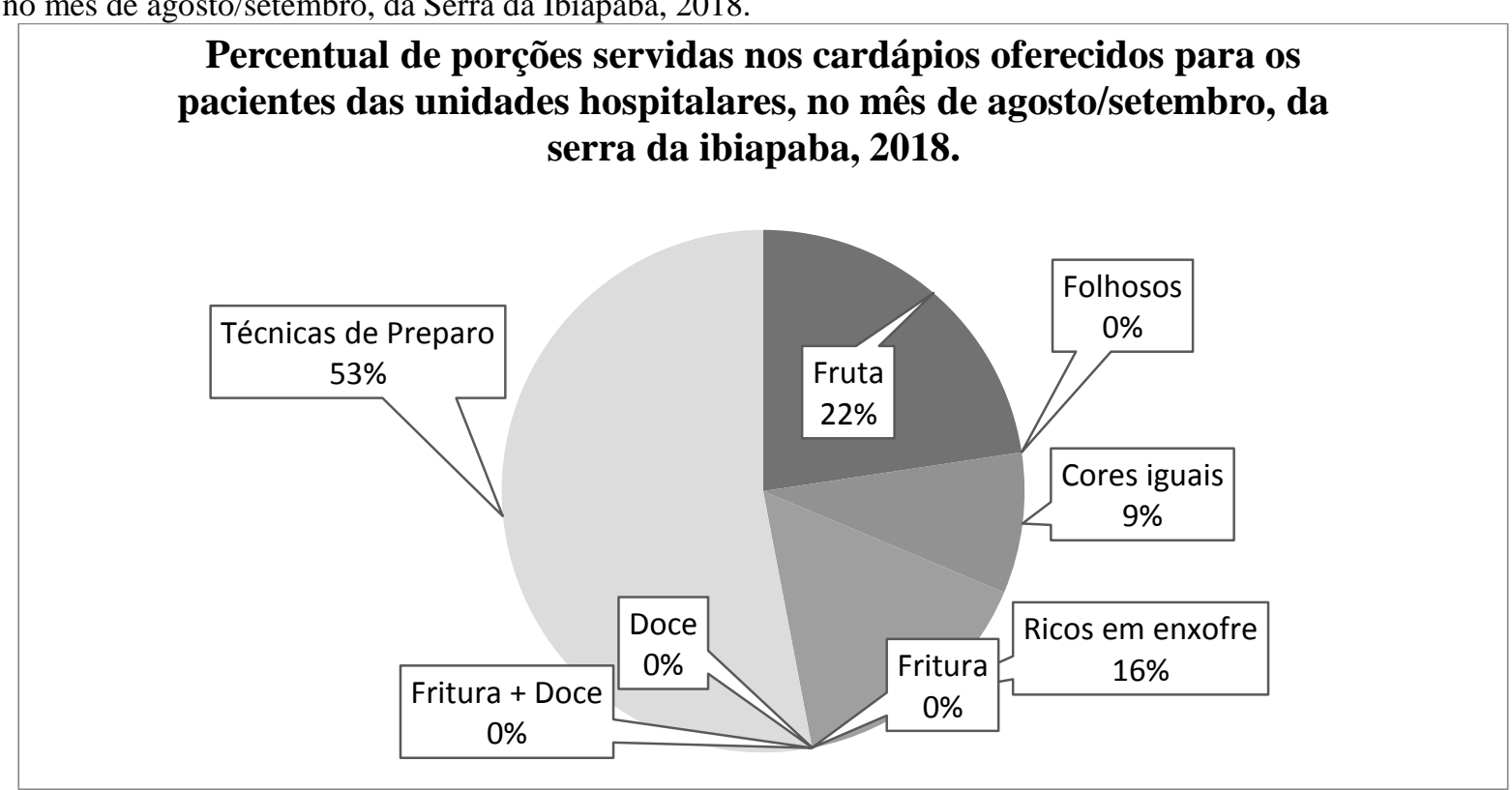

Fonte: Elaborada pelo autor. (2018)

Gráfico 2. Percentual de porções servidas nos cardápios oferecidos para os funcionários das unidades hospitalares, no mês de agosto/setembro, da Serra da Ibiapaba, 2018. 


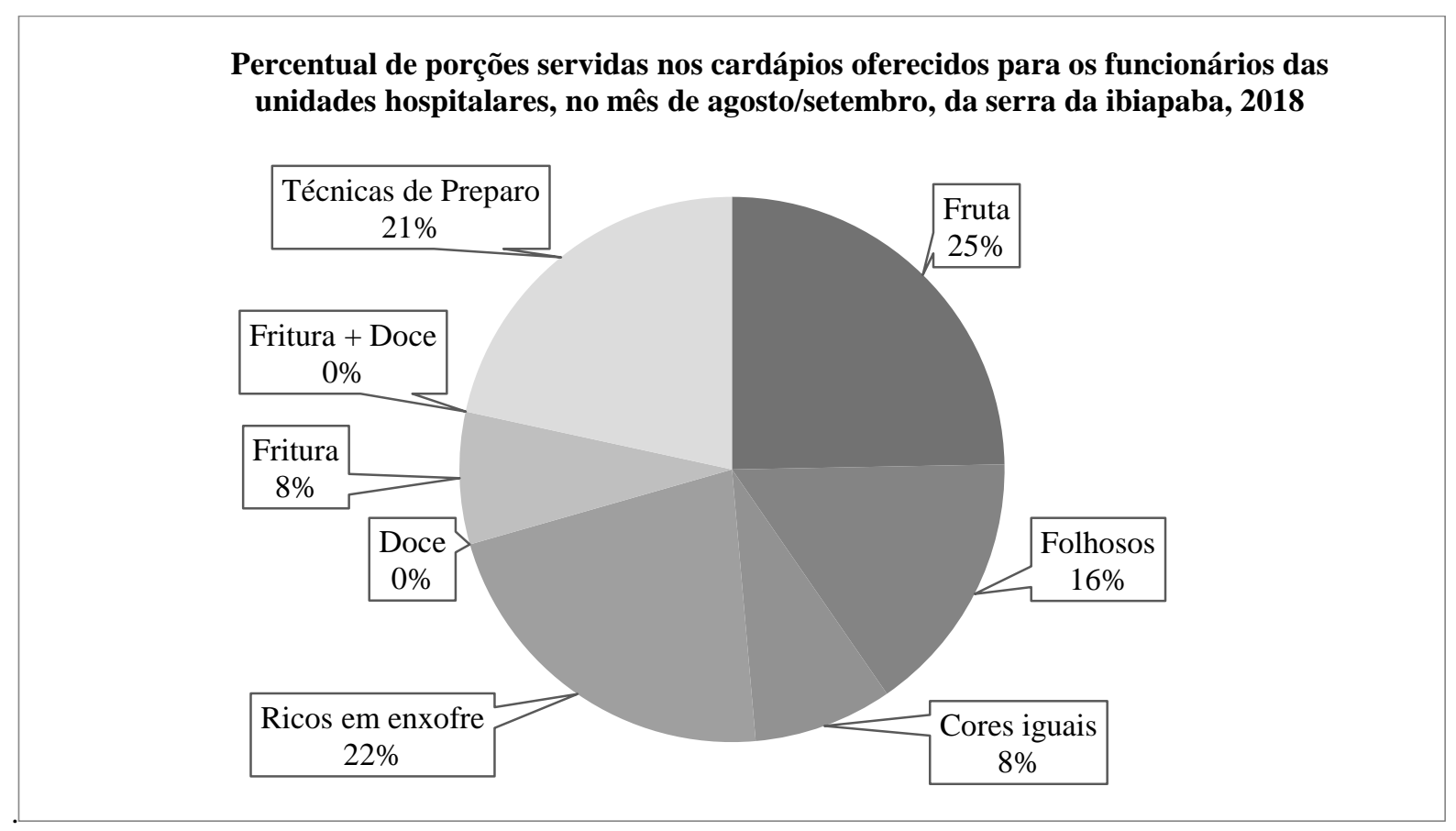

Fonte: Elaborada pelo autor. (2018)

$\mathrm{Na}$ cidade $\mathrm{D}$, os folhosos foram padrão para todos os dias do cardápio. Porém, apresentou como desvantagem a oferta diária de salada crua, que pode causar uma monotonia alimentar e também aumentar a formação de gases fermentadores, dependendo dos ingredientes das saladas.

Nos cardápios da cidade D, o critério mais alarmante foi a monotonia das preparações dos pacientes, considerando que a preparação é padrão para todos os dias. Ou seja, diariamente são servidos: Arroz, Feijão, Macarrão e Carne Moída com Legumes. Mas vale ressaltar que todas as unidades são de pequeno porte. Logo, o fluxo de pacientes internados é curto, permanecendo no hospital por 48h, aproximadamente.

As técnicas de preparação da cidade $\mathrm{D}$ demostraram poucas repetições, sendo o assado a técnica que mais se repetia. Destaca-se que o cardápio apresentava sucos diferenciados, com adição de pepino, couve e o hospital participa do Programa de Aquisição de Alimentos (PAA), que recebe alimentos de agricultura familiar. Então, não tem ingredientes fixos, pois o cardápio é elaborado de acordo com a entrega do PAA.

De acordo com o método AQPC, também são analisados itens como conservas, carnes gordurosas e duas ou mais frituras no mesmo dia. Porém, os cardápios elaborados não eram muito explicativos. E, como foram analisados apenas o almoço, com apenas uma opção de carne, não foi possível analisar o item de duas ou mais frituras servidas no mesmo dia. 
De acordo com o método aplicado, foi possível verificar que algumas unidades de alimentação não atendem aos itens avaliados pelo método AQPC, o que compromete o consumo variado de nutrientes.

O consumo de Frutas, Legumes e Verduras (FLV) são fontes de fibras dietéticas, que são substâncias não digeríveis pelo nosso organismo. As fibras fazem um papel de reguladoras, onde trabalham para a funcionalidade correta do intestino, além de ajudar na redução dos níveis de colesterol (FERRARI; TORRES, 2002).

A pirâmide alimentar brasileira determina que deve ser consumido no mínimo três porções de frutas por dia com o objetivo de reduzir as doenças cardiovasculares e até mesmo alguns tipos de câncer (BRASIL, 2014). Nenhuma UAN oferece folhosos na alimentação dos pacientes e pesquisas mostram que os compostos presentes em frutas, legumes e verduras apresentam substâncias químicas com propriedades antioxidantes e anti-inflamatórias, de grande importância para a prevenção de doenças (BRASIL, 2014).

A monotonia de cores foi um dos itens que foi considerado satisfatório. No entanto, não foi possível analisar com maior precisão, tendo em vista que o cardápio foi analisado somente formalmente. O jogo de cores na montagem do prato é muito importante, pois uma montagem com cores iguais não despertam interesse do comensal e isso pode trazer várias consequências, como o aumento do desperdício da refeição e aumento do tempo de internamento hospitalar, diante do baixo consumo de nutrientes (PEREZ et al. 2002; VEIROS; PROENÇA, 2003; SOUSA et al., 2005).

De acordo com o Inquérito Brasileiro de Avaliação Nutricional Hospitalar IBRANUTRI (que tem como objetivo de investigar a desnutrição hospitalar no Sistema Único de Saúde - SUS, realizado em 12 estados brasileiros, totalizando 25 hospitais e 4 mil pacientes), foi possível observar uma média de 48,1\% de desnutrição hospitalar, sendo 12,6\% desnutridos graves e $35,5 \%$ moderados. Também foi possível observar que a região mais crítica foi a Norte/Nordeste, ficando com 36,1\% nutridos, $43,8 \%$ desnutridos moderados e $20,1 \%$ desnutridos graves (WAITZBERG et al., 2001).

Ao analisar os cardápios, foi possível perceber que apenas um oferecia pratos regionais, conhecido como Maria Isabel. Corbeau (1998) cita em um de seus trabalhos que o setor da alimentação hospitalar tem por dever conhecer os hábitos culturais do local e dos pacientes, pois a alimentação é mais do que o ato de nutrir. Ou seja, é fonte de prazer, faz parte da manutenção da vida e auxilia na reconstrução da saúde. 
Durante o preparo das refeições é importante que os sabores devam estar em equilíbrio sendo eles os ácidos, salgado, apimentado, amargo, doce, picante, suave, azedo, sempre tomando cuidado para que não se repitam. Diversificar os métodos de alguns componentes do prato deixam a refeição variada em sua aparência e no sabor (TEICHMAN, 2000).

Segundo Bezerra (2003), em seu trabalho em uma unidade hospitalar com o objetivo de verificar o que fazer para melhorar a refeição, verificou-se que as principais sugestões são: acrescentar mais tempero; variar mais a carne e o cardápio; aumentar a quantidade de frutas; melhorar a decoração dos pratos e melhorar a apresentação das refeições.

Nos gráficos 3 e 4 que mostram os níveis de adequação dos cardápios, foi possível verificar um baixo consumo de frituras nos cardápios dos pacientes e funcionários, apresentando $97,8 \%$ e $89,1 \%$, respectivamente. Com isso os cardápios ficaram no grupo dos muito satisfatórios. Segundo Souza (2017), em uma pesquisa utilizando o método (AQPC) para cardápios de UANs institucionais, do tipo hospitalar, restaurante universitário e empresas que forneciam refeição aos seus colaboradores. Apresentou os níveis de fritura parecido com o encontrado no atual trabalho, ficando também no grupo dos muito satisfatórios, com 87,18\% de adequação.

Infelizmente, não foi possível analisar alguns itens e um deles foi as carnes gordurosas, pois nenhum dos seis cardápios analisados especificou o tipo de carne servida. O consumo de carnes gordurosas não é benéfico para os comensais, pois pode elevar os níveis de colesterol e triglicerídeos, entre outras disfunções nos organismos (GIONGO; CABRAL, 2012).

Gráfico 3. Percentual de adequação e inadequação dos cardápios dos pacientes, segundo os critérios da Avaliação da Qualidade das Preparações dos Cardápios da Serra da Ibiapaba, 2018.
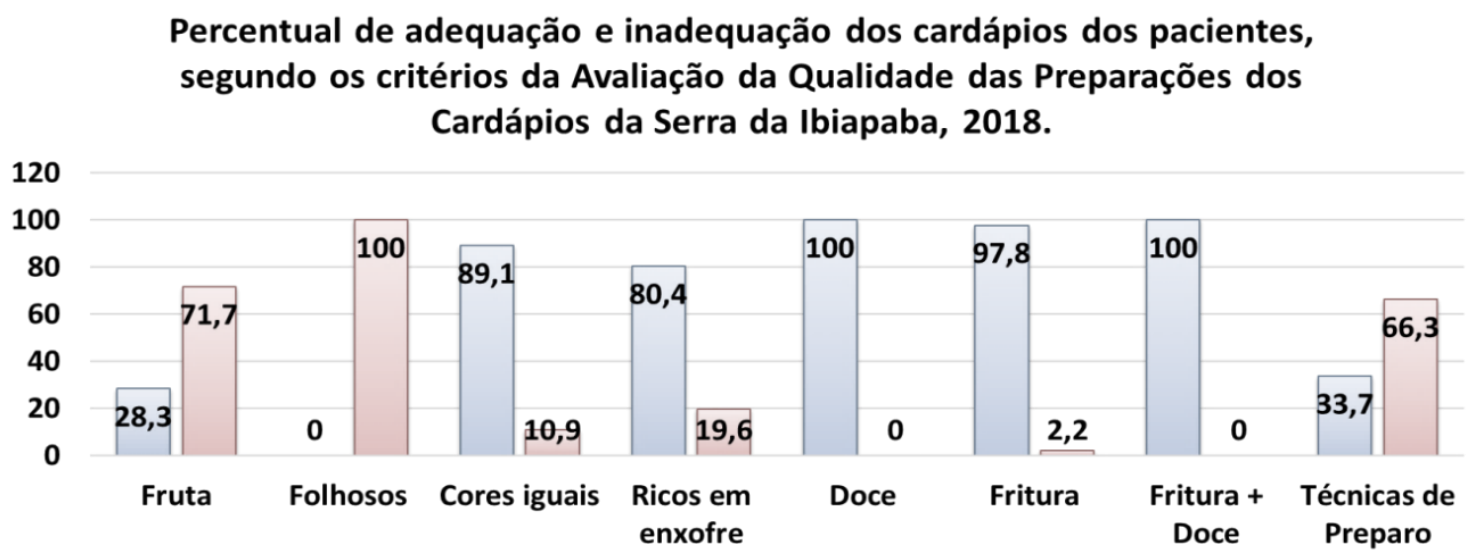

$\square$ Adequado $\square$ Não Adequado

Fonte: Elaborada pelo autor (2018)

Gráfico 4. Percentual de adequação e inadequação dos cardápios dos funcionários, segundo os critérios da Avaliação da Qualidade das Preparações dos Cardápios da Serra da Ibiapaba, 2018.

[616] 


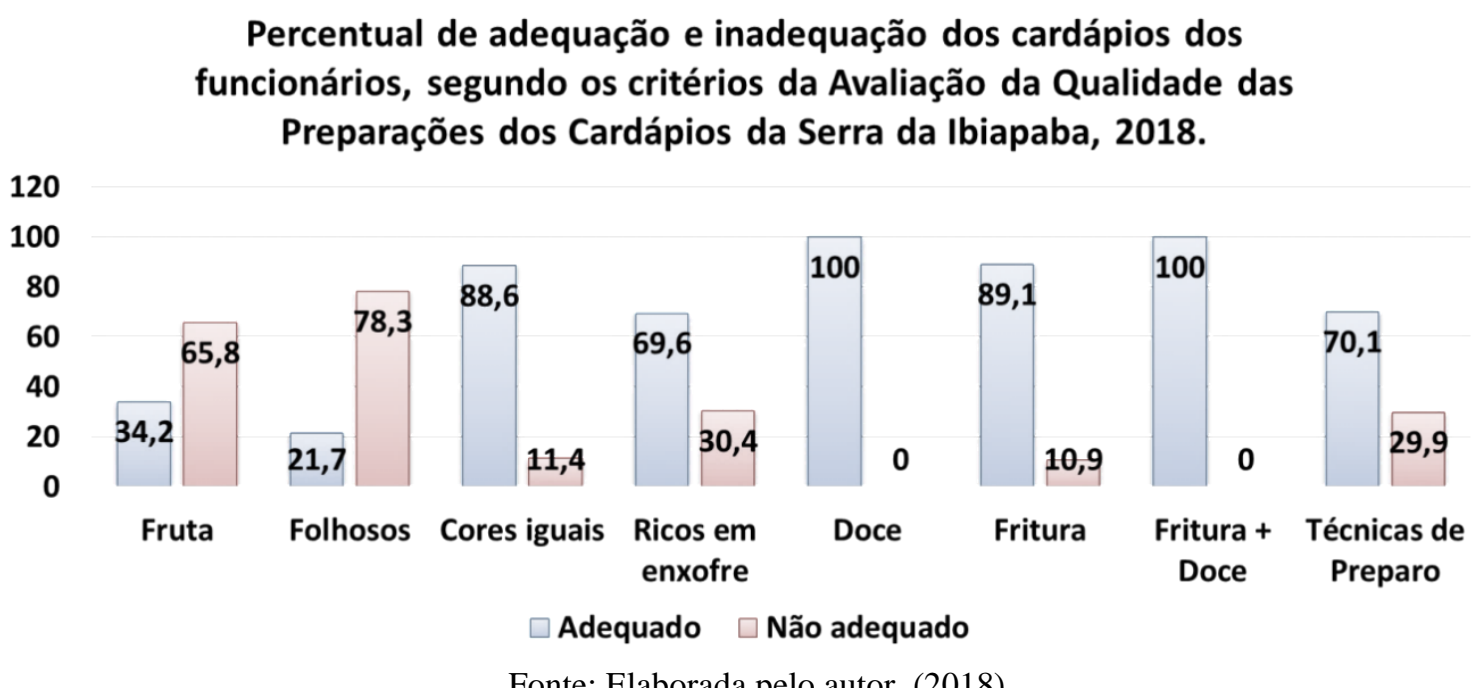

\section{Conclusões}

Conclui-se que as refeições oferecidas tiveram uma baixa oferta de FLV, principalmente de folhosos. Os cardápios dos pacientes apresentaram poucas opções de alimentos fontes de enxofre em comparação com a dos funcionários, o que vem ajudando para reduzir o desenvolvimento de gases formadores em pacientes internados no hospital.

O item de maior adequação foi a oferta de doces, tanto no cardápio de pacientes como no de funcionários, que apresentaram $0 \%$ de oferta.

A gastronomia hospitalar surgiu para intervir na alimentação hospitalar e transformar uma refeição pobre em temperos e condimentos. Ainda é muito complicado trabalhar com o realce do sabor nessas unidades, pois a gastronomia hospitalar encontra muitos desafios, diante de várias restrições de ingredientes básicos utilizados para conferir mais sabor as refeições. Sem contar, ainda, o fato de que também exige muita criatividade.

Outro desafio é a inclusão de pratos regionais, pois isso implica em uma maior aceitação do cardápio, considerando os hábitos culturais juntamente com o uso das técnicas dietéticas adequadas.

\section{Referências}

BEZERRA, A. C. Gastronomia na prescrição de dietas hospitalares e as influências geradas pela indústria hoteleira. 2003. 47p. Monografia (especialização) Universidade de Brasília. Centro de Excelência em Turismo. Brasília, 2003.

BOEGER, M. A. Gestão em hotelaria hospitalar. São Paulo: Atlas, 2005. 
BRASIL. Ministério da Saúde. Secretaria de Atenção à Saúde. Guia alimentar para a população brasileira: promovendo a alimentação saudável. 2. ed. Brasília: Ministério da Saúde, 2014.

BRITO, L. F.; BEZERRA, V. M. Avaliação qualitativa das preparações do cardápio de uma unidade de Vitória da Conquista. Alimentos e Nutrição Araraquara, Bahia, v. 24, n. 2, p. $158,2013$.

CORBEAU, J. P. S'alimenter à l'hôpital: les dimensions caches de la commensalité. In: Assistance Publique:Hôpitaux Paris, Láppétit vient en mangeant! Histoire de lálimentation à l'hôpital. XV - XX siècle. Paris: Edoin Editeurs e Musée de l'Ássistence Publique, 1998. p. 101-14.

DICKINSON, A.; WELCH, C.; AGER, L.; COSTAR, A. Hospital Mealtimes: action research for change? Proceedings of the Nutrition Society, v. 64, n. 3, p. 269-275, 2005.

FERRARI, C. K. B.; TORRES, E. A. F. S. Alimentos funcionais: quando a boa nutrição melhora a nossa saúde. Revista Portuguesa de Saúde Pública, Lisboa, v. 20, n. 2, 2002, p.3134

GINANI, V. C. Avaliação da qualidade nutricional, sensorial e cultural de cardápios populares. 2011, 131 f., tese (Pós-graduação em Nutrição Humana) - Faculdade de Ciências da Saúde, Universidade de Brasília, Brasília, 2011

GIONGO, V.; CABRAL, L. Avaliação do Risco Potencial de Doenças Coronarianas em Dietas com Alto Consumo de Carnes Vermelhas. Estudo Investigativo sobre Indicadores de Câncer Colorretal. Revista Eletrônica Novo Enfoque, 2012, 15(Edição Especial): 20-24.

GUIMARÃES, N.V. Hotelaria hospitalar: uma visão interdisciplinar. São Paulo: Atheneu, 2007.

LINS, Magnoni. Gastronomia hospitalar: conceitos $\mathrm{r}$ verdades. In: ROBERTO, T. S. Gastronomia hospitalar no conceito do comfort food. São Paulo: Livraria brasileiro, 2013. p.3435 .

MIRSHAWKA, V. Hospital: fui bem atendido, a vez do Brasil. São Paulo: Makron Books, 1994.

PEDROSA, C. G. Cuidado alimentar e nutricional ao paciente hospitalizado: elementos para a construção de um modelo fundamentado na humanização. 2007, 133 f. Dissertação(Mestrado). Florianópolis: UFSC, 2007.

PEREZ, J.I.U.; PICÓN, C.M.J.; BENAVENT, E.G.; A. ALVAREZ, E.M. Detección precoz y control de la desnutrición hospitalaria. Nutr Hosp 2002; v. 17, n. 3, p. 139-146.

PROENÇA, R.P.C.; SOUSA, A.A.; VEIROS, M.B.; HERING, B. Qualidade nutricional e sensorial na produção de refeições. Florianópolis: UFSC, 2005. 221 p.

ROBERTO, T. S. Gastronomia hospitalar no conceito do comfort food. São Paulo: Livraria brasileiro, 2013. 5p. 
SILVA, S. M. C. S.; MARTINEZ, S. Cardápio: guia prático para elaboração. 2. ed. São Paulo: Atheneu, 2008. 279p.

SOUSA, A. A.; GLORIA, M.S.; CARDOSO, T. S. Aceitação de dietas em ambiente hospitalar. Revista de Nutrição, v. 24, n. 2, 2011, p.287-294.

SOUZA Y. D. C. Análise da qualidade de cardápios de unidades de alimentação e nutrição de Goiânia - GO. 2017. Monografia (Graduação em Nutrição) Faculdade de Nutrição(fanut), Universidade Federal de Goiás, Goiânia, 2017.

SOUZA, M.D.; MIYOKO, N. A Gastronomia Hospitalar Auxiliando na Redução dos Índices de Desnutrição entre pacientes Hospitalizados. O Mundo da Saúde, 35(2), pp. 208214, são Paulo, 2011.

TEICHMAN, I. M. Cardápios - técnicas e criatividade. Caxias do Sul: EDUCS, 2000. (Hotelaria).

VEIROS, M.B.; PROENÇA, R.P.C. Avaliação qualitativa das preparações do cardápio de uma unidade de alimentação de nutrição - método AQPC. Nutrição em Pauta, São Paulo, v.12, n. 62, set./out. 2003, p. 36-42.

VIEIRA, M. N. C. M.; JAPUR C. C. Gestão da qualidade na produção de refeições. Rio de Janeiro: Guanabara Koogan, 2015.

WAITZBERG, D.L.; WALESKA, T.; CAIAFFA, M.D. CORREIA, I.T.D. Hospital malnutrition: the Brazilian National Survey (IBRANUTRI): A study of 4000 patients. Nutrition, v. 17, n.7/8, 2001, p. 553-580. 